\title{
An Approach to Optimize MIG Welding Parameters by Using Design of Experiments
}

\author{
Priti Sonasale \\ Department Of Mechanical Engineering Central University Of Karnataka Gulbarga, Karnataka, India.
}

\begin{abstract}
The Metal arc Welding (MIG) process finds wide application because all commercially important applicable metals such as carbon steel, high-strength, low-alloy steel, and stainless steel, aluminum, copper, titanium, and nickel alloys can be welded in all positions with this process by choosing the appropriate shielding gas, electrode, and welding variables. In this work, the five control factors such as wire feed rate, arc voltage, welding speed, nozzle to plate distance and gas flow rate are considered.The welding parameters such as bead width, dilution and depth of HAZ have been considered.By using DOE method, the weld parameters were optimized. Analysis is done using ANOVA to determine the significance of parameters. Finally the confirmation test is carried out to compare the predicated values with the experimental values confirm its effectiveness in the analysis of bead width, dilution and depth of HAZ.
\end{abstract}

Key words:MIG Welding, Mild steel, DOE, ANOVA

\section{Introduction}

With the introduction of welding as joining method, the welding technology was applied as major joining technique in hi-tech industries to the weldingof steels for manufacturing of different structures like pressure vessels and aerospace applications.Mostly high strength low alloy steels in thin cylindrical shell form are being used for aerospace structures due to high strength and low weight ratio. The mechanical properties of a weldment depend largely on bead geometry parameters such as depth of HAZ, dilution and bead width. MIG is a multi-objective, multi-factor metal fabrication technique $[1,3]$. Several process parameters interact in a complex manner resulting in direct or indirect influence on bead geometry and hence on the mechanical behavior of the welds prepared by this process. Hence, it is necessary to find an optimal process condition in terms of welding parameters such as, Wire feed rate, Arc Voltage,Welding Speed, Nozzle to Plate Distance,Gas flow rate to obtain the optimum bead geometry. Detailed analysis using statistical methods like factorial techniques have been employed by researchers to correlate these parameters with weld bead geometry, weld quality, etc [4-7]. Purohit [8] has determined bead geometry parameters for metal inert gas (MIG) underwater welded bead-on-plates using 2-level factorial design of experiments. Gunaraj and Murugan [9] have used 5-level factorial experiments to determine the main and interaction effects of process control variables on important bead geometry parameters including bead volume quantitatively and optimal bead volume with maximum penetration, minimum reinforcement and bead width have been obtained successfully. Of late, Taguchi techniques areused extensively for solving optimization problems in the field of production engineering [10]. This method utilizes a well balanced experimental design consisting of a limited number of experimental runs, called orthogonal array $(\mathrm{OA})$ and signal-to-noise ratio $(\mathrm{S} / \mathrm{N})$ which serve the objective function to be optimized within experimental limits. Further, to determine the significance of factors on the responses analysis of variance (ANOVA) is used. This paper presents the details of an experimental work on surfacing of mild steel by chromium and manganese alloy steel by MIG process to yield desired quality of surfacing, in terms of bead geometry, as influenced by Wire feed rate, Arc Voltage, Welding Speed, Nozzle to Plate distance, Gas flow rate which are varied at three different levels. Orthogonal array Taguchi approach has been carried out to solve this multi-response optimization problem [11].

\section{Design of experiment based on the Taguchi method}

The experiments have been performed by MIG Welding Machine. ACESS MIG 400 Copper coated electrode wire of diameter 1.2mm [AWSER 70S-6].Gases used are Argon 98\% and $\mathrm{CO}_{2} 2 \%$. After surfacing transverse sections of the weld bead have been cut from the middle portions of the plates by grinding cutting machine as shown in the figure1 A \& B. 

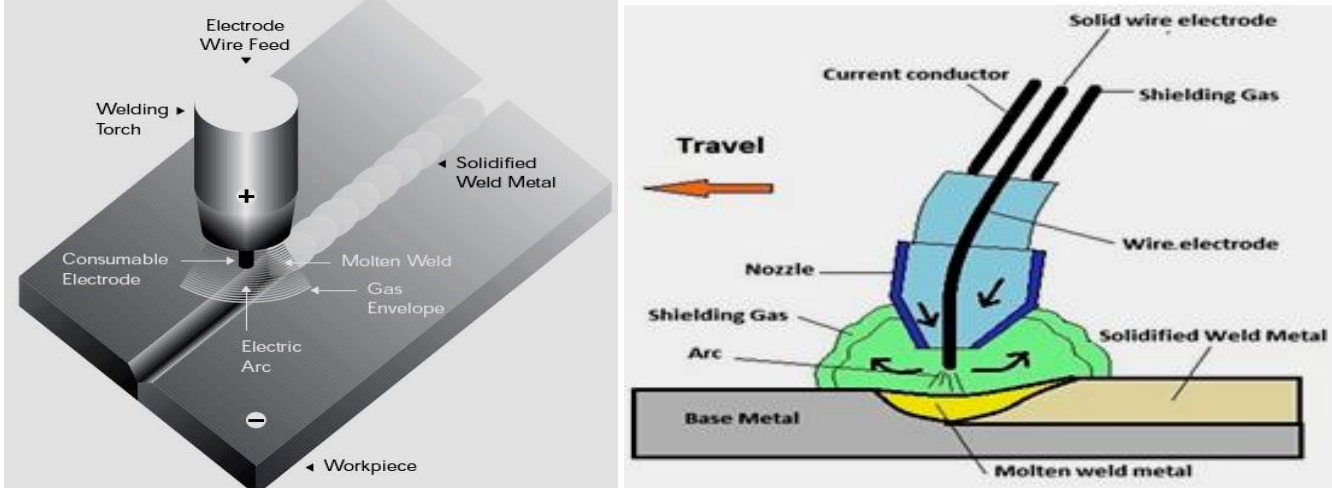

Figure 1 A:Working condition of Work piece Figure 1 B:Working principles of GMAW

The specimens have been polished by fine abrasive papers followed by the emery papers of grades1, $1 / 0,2 / 0,3 / 0$ and $4 / 0$ finally they have been smoothened by means of cloth polishing as shown in fig 2 . The properly polished specimens have been etched with $2 \%$ Nital solution for about 30 sec.
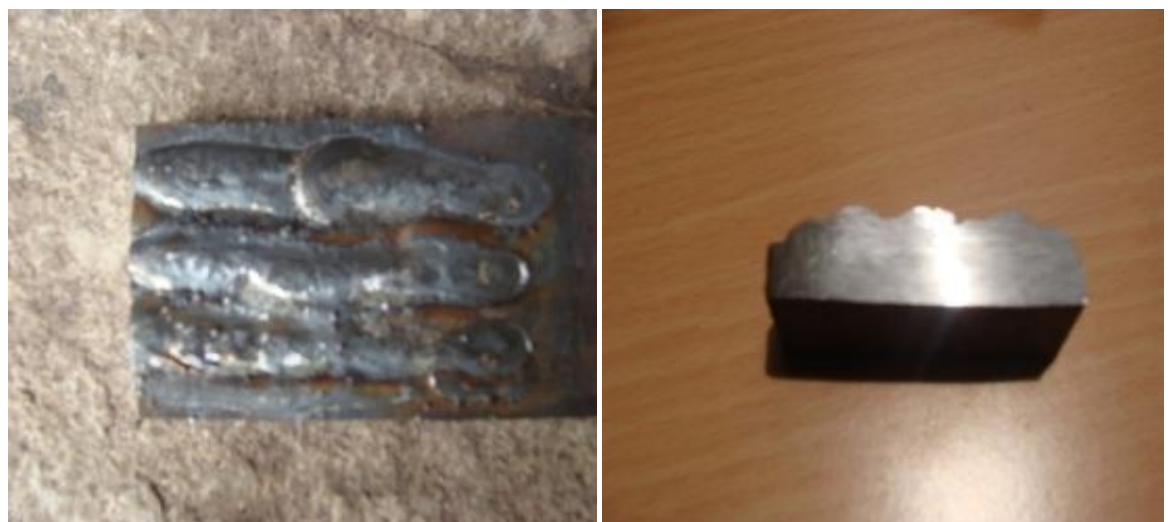

Figure: 2showing cutting section of the hardfaced plate

The Microstructure of the sample is observed in light optical microscope as shown in figure 3

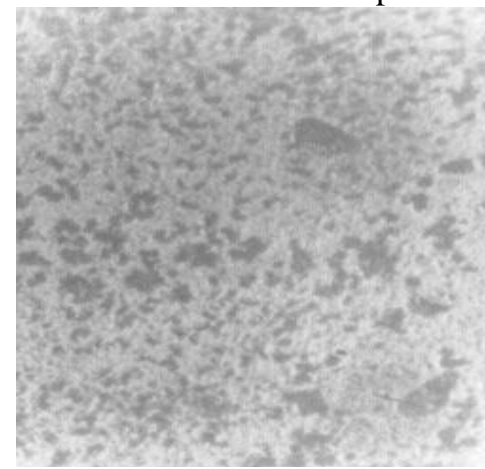

Sample No: 3

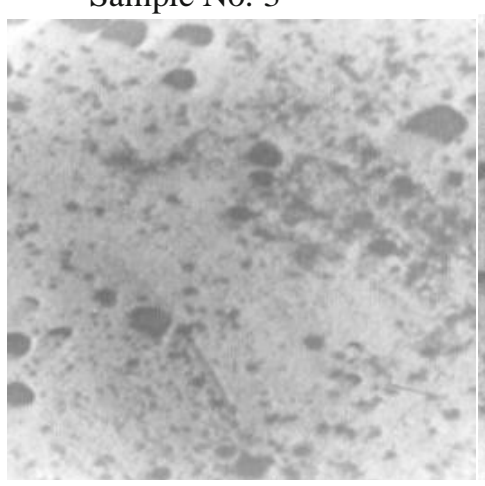

Sample No: 14
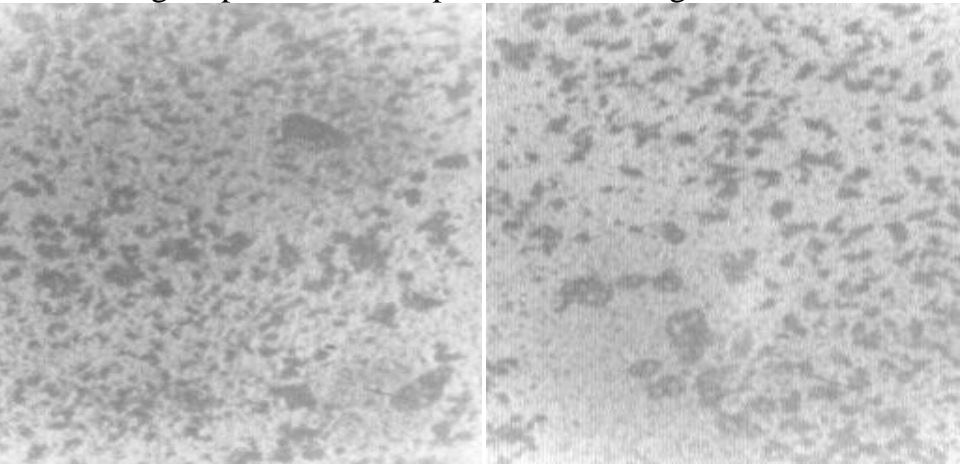

Sample No: 6

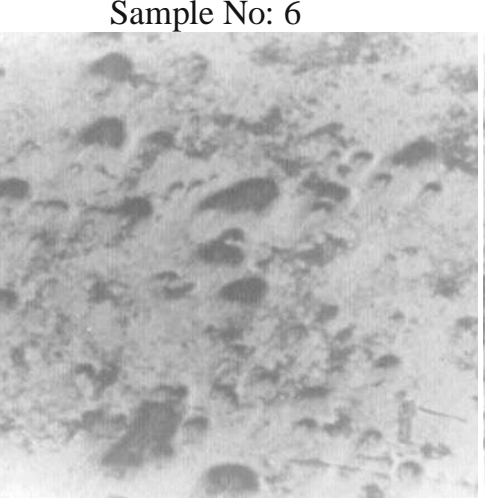

Sample no: 18

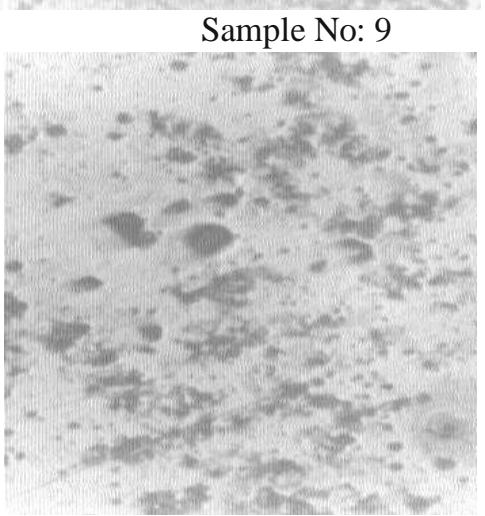

Sample No :20

Figure 3: Microstructure of the specimens 
Taguchi's $L_{27}$ orthogonal array has been selected to restrict the number of experimental runs. Experiments have been conducted with these process control parameters to obtain bead-on-plate surfacing on mild steel plates of thickness of dimension [50 x 100 x 08] mm by MIG Welding(MIG). Design matrix has been selected based on Taguchi's $L_{27}$ orthogonal array consisting 27 sets of coded condition.

Table 1: Welding Process Parameters

\begin{tabular}{|l|l|l|l|l|l|}
\hline \multirow{2}{*}{ Control Factors } & \multirow{2}{*}{ Notation } & \multicolumn{3}{|c|}{ Levels } & \multirow{2}{*}{ units } \\
\cline { 3 - 5 } & & \multicolumn{1}{|c|}{ I } & II & III & \\
\hline Wire feed rate & A & 0.5 & 1.0 & 1.5 & Ipm \\
\hline Arc Voltage & B & 30 & 32 & 34 & Volt \\
\hline Welding Speed & C & 8 & 10 & 12 & Sec/cm \\
\hline Nozzle to Plate Distance & D & 10 & 13 & 18 & $\mathrm{~mm}$ \\
\hline Gas flow rate & E & 10 & 13 & 18 & $\mathrm{Lit} / \mathrm{min}$ \\
\hline
\end{tabular}

The most important performance measures for MIG welding process are Bead Width $\left(B_{w}\right)$, Dilution $\left(D_{i}\right)$ and Depth of HAZ $\left(D_{H}\right)$. Welding performance in MIG Process is mainly expressed as higher value of Bead Width and smaller values of Dilution and Depth of HAZ. Bead Width is higher-the-better performance characteristics while Dilution and Depth of HAZ are smaller-the-better performance characteristic. For the Experimental plan, the taguchi method of three level experiments was chosen.Table 1 indicates the factors to be studied and their preferred levels that can be controlled through the experimental process. Assignment of factors to various columns was made in accordance with the linear graph as shown in the figure 4, for an $L_{27}\left(3^{13}\right)$ orthogonal array (Peace, 1993: Phadke, 1989.

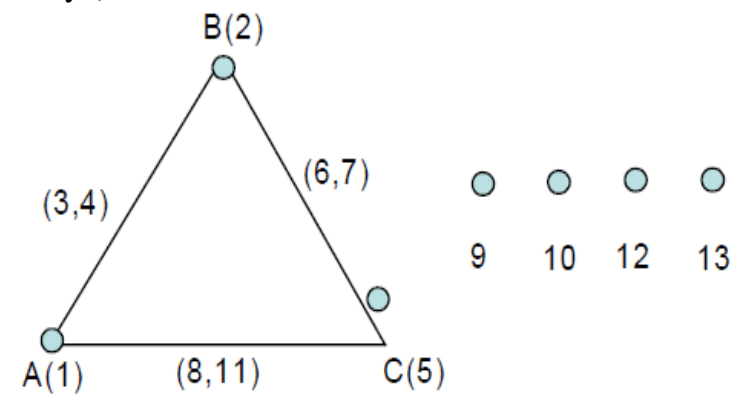

Figure 4: Standard linear graph for $L_{27}$ array

The detailed orthogonal array is shown in the table2. The chosen experimental design has 27 rows corresponding to the number of experiments with 13 columns at three levels, as shown in the table 2 . The plan required 27 experimental runs, in which the first column was assigned to Wire feed rate(A), the second column to Arc Voltage(B), the fifth column to Welding Speed (C), the ninth column to Nozzle to Plate Distance(D), and tenth column to Gas flow rate $(\mathrm{E})$, the third and fourth column were assigned to $(\mathrm{AxB})_{1}$ and $\left.\mathrm{AxB}\right)_{2}$ respectively to estimate the interaction between Wire feed rate (A) and Arc Voltage (B), the sixth and seventh columns to $(\mathrm{BxC})_{1}$ and $(\mathrm{BxC})_{2}$ respectively to estimate the interaction between Arc Voltage(B) and Welding Speed $(\mathrm{C})$, the eighth and eleventh columns to $(\mathrm{AxC})_{1}$ and $(\mathrm{AxC})_{2}$ respectively to estimate the interaction between to Wire feed rate(A) and Welding Speed (C). Two replications under each combination of factors were used and performance output was calculated as average of two values. The experimental observations were further transformed into signal-to-noise $(\mathrm{S} / \mathrm{N})$ ratio. 


\begin{tabular}{|c|c|c|c|c|c|c|c|c|c|c|c|c|c|}
\hline & 1 & 2 & 3 & 4 & 5 & 6 & 7 & 8 & 9 & 10 & 11 & & \\
\hline $\mathrm{L}_{27}\left(3^{19}\right)$ & A & B & $(\mathrm{AXB})$ & $\left(\mathrm{AXB}_{2}\right.$ & C & $(\mathrm{BXC})_{1}$ & $(\mathrm{BXC})_{2}$ & $(\mathrm{AXC})_{1}$ & D & E & $(\mathrm{AXC})_{2}$ & 12 & 13 \\
\hline 1 & 1 & 1 & 1 & 1 & 1 & 1 & 1 & 1 & 1 & 1 & 1 & 1 & 1 \\
\hline 2 & 1 & 1 & 1 & 1 & 2 & 2 & 2 & 2 & 2 & 2 & 2 & 2 & 2 \\
\hline 3 & 1 & 1 & 1 & 1 & 3 & 3 & 3 & 3 & 3 & 3 & 3 & 3 & 3 \\
\hline 4 & 1 & 2 & 2 & 2 & 1 & 1 & 1 & 2 & 2 & 2 & 3 & 3 & 3 \\
\hline 5 & 1 & 2 & 2 & 2 & 2 & 2 & 2 & 3 & 3 & 3 & 1 & 1 & 1 \\
\hline 6 & 1 & 2 & 2 & 2 & 3 & 3 & 3 & 1 & 1 & 1 & 2 & 2 & 2 \\
\hline 7 & 1 & 3 & 3 & 3 & 1 & 1 & 1 & 3 & 3 & 3 & 2 & 2 & 2 \\
\hline 8 & 1 & 3 & 3 & 3 & 2 & 2 & 2 & 1 & 1 & 1 & 3 & 3 & 3 \\
\hline 9 & 1 & 3 & 3 & 3 & 3 & 3 & 3 & 2 & 2 & 2 & 1 & 1 & 1 \\
\hline 10 & 2 & 1 & 2 & 3 & 1 & 2 & 3 & 1 & 2 & 3 & 1 & 2 & 3 \\
\hline 11 & 2 & 1 & 2 & 3 & 2 & 3 & 1 & 2 & 3 & 1 & 2 & 3 & 1 \\
\hline 12 & 2 & 1 & 2 & 3 & 3 & 1 & 2 & 3 & 1 & 2 & 3 & 1 & 2 \\
\hline 13 & 2 & 2 & 3 & 1 & 1 & 2 & 3 & 2 & 3 & 1 & 3 & 1 & 2 \\
\hline 14 & 2 & 2 & 3 & 1 & 2 & 3 & 1 & 3 & 1 & 2 & 1 & 2 & 3 \\
\hline 15 & 2 & 2 & 3 & 1 & 3 & 1 & 2 & 1 & 2 & 3 & 2 & 3 & 1 \\
\hline 16 & 2 & 3 & 1 & 2 & 1 & 2 & 3 & 3 & 1 & 2 & 2 & 3 & 1 \\
\hline 17 & 2 & 3 & 1 & 2 & 2 & 3 & 1 & 1 & 2 & 3 & 3 & 1 & 2 \\
\hline 18 & 2 & 3 & 1 & 2 & 3 & 1 & 2 & 2 & 3 & 1 & 1 & 2 & 3 \\
\hline 19 & 3 & 1 & 3 & 2 & 1 & 3 & 2 & 1 & 3 & 2 & 1 & 3 & 2 \\
\hline 20 & 3 & 1 & 3 & 2 & 2 & 1 & 3 & 2 & 1 & 3 & 2 & 1 & 3 \\
\hline 21 & 3 & 1 & 3 & 2 & 3 & 2 & 1 & 3 & 2 & 1 & 3 & 2 & 1 \\
\hline 22 & 3 & 2 & 1 & 3 & 1 & 3 & 2 & 2 & 1 & 3 & 3 & 2 & 1 \\
\hline 23 & 3 & 2 & 1 & 3 & 2 & 1 & 3 & 3 & 2 & 1 & 1 & 3 & 2 \\
\hline 24 & 3 & 2 & 1 & 3 & 3 & 2 & 1 & 1 & 3 & 2 & 2 & 1 & 3 \\
\hline 25 & 3 & 3 & 2 & 1 & 1 & 3 & 2 & 3 & 2 & 1 & 2 & 1 & 3 \\
\hline 26 & 3 & 3 & 2 & 1 & 2 & 1 & 3 & 1 & 3 & 2 & 3 & 2 & 1 \\
\hline 27 & 3 & 3 & 2 & 1 & 3 & 2 & 1 & 2 & 1 & 3 & 1 & 3 & 2 \\
\hline
\end{tabular}

Table 2: Orthogonal Array for $\mathrm{L}_{27}\left(3^{13}\right)$ Taguchi Design

There are several $\mathrm{S} / \mathrm{N}$ ratios available depending on the type of performance characteristics that higher value represents better performance, such as bead width, 'Higher is Better(HB)' characteristics were used. Inversely the characteristic that lower value represents better performance, such as dilution and Depth of HAZ. 'Lower is better (LB)' characteristic was used. The loss function (L) for the objectives of HB and LB is defined as follows:

$$
\begin{aligned}
& L_{H B}=\frac{1}{n} \sum_{i=0}^{n} \frac{1}{B_{W}^{2}} \\
& L_{L B}=\frac{1}{n} \sum_{i=0}^{n} D_{i}^{2}
\end{aligned}
$$

$$
L_{L B}=\frac{1}{n} \sum_{i=0}^{n} D_{H}^{2}
$$

Where $B_{w}, D_{i}$ and $D_{H}$ represents the response for bead width, dilution and depth of HAZ respectively and 'n' denotes the number of experiments.

The Signal-to-Noise (S/N) ratio can be expressed as the logarithmic transformation of loss function, as shown in equations (4), (5) and (6) for bead width, dilution and depth of HAZ respectively.

$\mathrm{S} / \mathrm{N}$ ratio for $B_{w}=-\log _{10} L_{H B}$
$\mathrm{~S} / \mathrm{N}$ ratio for $D_{i}=-\log _{10} L_{L B}$
$\mathrm{~S} / \mathrm{N}$ ratio for $D_{H}=-\log _{10} L_{L B}$

(6) 


\section{Results and discussion}

The experimental results are tabulated in table 3 . The overall mean for $\mathrm{S} / \mathrm{N}$ Ratio of Bead width $\left(B_{w}\right)$, dilution $\left(D_{i}\right)$ and Depth of $\mathrm{HAZ}\left(D_{H}\right)$ is found to be $21.66 \mathrm{~dB},-30.73 \mathrm{~dB}$ and $-2.53 \mathrm{~dB}$ respectively. Analysis of experimental data was carried out using the popular software known as Minitab 17. The effects of five control factors on performance measures $B_{w}, D_{i}$ and $D_{H}$ are shown graphically in the figures respectively.

Before any attempt is made to use this simple model as a predictor of the measures of performance, the possible interactions between factors must be considered. Factorial design incorporates a simple means of testing for the presence of interaction effects. The $\mathrm{S} / \mathrm{N}$ Ratio response tables for performance measures $B_{w}, D_{i}$ and $D_{H}$ are depicted in table 4,5 , and 6 respectively.

An interesting phenomenon can be observed from the table 4 - that factors $\mathrm{B}$ and $\mathrm{C}$ do not show any significant effect individually in comparison to factor $\mathrm{A}$ for improving $B_{w}$, but their interaction with factor $\mathrm{A}$ and with each other is quite significant. The interaction graphs between the factors $\mathrm{A} \times \mathrm{B}, \mathrm{B} \times \mathrm{C}$ and $\mathrm{A} \times \mathrm{C}$ on $B_{w}$ are shown in the figures 8,9 , and 10 respectively. Therefore careful analysis of the response table (table 4) and figures 5, 8, 9 and 10 leads to the conclusion that the maximum value of $B_{w}$ can be achieved if control factors are set at levels $A_{2}, B_{2}, C_{3}, D_{3}$ and $E_{1}$

Table 3: Taguchi Experimental Design using $L_{27}$ Orthogonal Array

\begin{tabular}{|c|c|c|c|c|c|c|c|c|c|c|c|}
\hline Expt.No: & A & B & c & D & E & Bead width & $\begin{array}{l}\text { SNRA1 } \\
(\mathrm{dB})\end{array}$ & $\%$ Dilution & $\begin{array}{l}\text { SNRAI } \\
(\mathrm{dB})\end{array}$ & Depth Of HAZ & $\begin{array}{l}\text { SNRAI } \\
\text { (dB) }\end{array}$ \\
\hline 1 & 1 & 1 & 1 & 1 & 1 & 11.2 & 2098436 & 42.8 & -32.629 & 1.4 & -29226 \\
\hline 2 & 1 & 1 & 2 & 2 & 2 & 11 & 20.82785 & 42.8 & -32.629 & 13 & -22789 \\
\hline 3 & 1 & 1 & 3 & 3 & 3 & 12 & 21.58362 & 50 & -33979 & 12 & -1.5836 \\
\hline 4 & 1 & 2 & 1 & 2 & 2 & 12.4 & 21.86843 & 42.5 & -32.568 & 12 & -1.5836 \\
\hline 5 & 1 & 2 & 2 & 3 & 3 & 11.6 & 21.28916 & 40 & -32.041 & 13 & -2.2789 \\
\hline 6 & 1 & 2 & 3 & 1 & 1 & 10.8 & 20.66848 & 41.7 & -32.403 & 15 & -3.5218 \\
\hline 7 & 1 & 3 & 1 & 3 & 3 & 11.2 & 2098436 & 333 & -30.449 & 1.4 & -2.9226 \\
\hline 8 & 1 & 3 & 2 & 1 & 1 & 12 & 21.58362 & 33.5 & -30.501 & 1.4 & -2.9226 \\
\hline 9 & 1 & 3 & 3 & 2 & 2 & 11.8 & 21.43764 & 375 & -31.481 & 1.5 & -3.5218 \\
\hline 10 & 2 & 1 & 1 & 2 & 3 & 12.2 & 21.7272 & 333 & -30.449 & 1.4 & -2.9226 \\
\hline 11 & 2 & 1 & 2 & 3 & 1 & 11.8 & 21.43764 & 333 & -30.449 & 1.4 & -2.9226 \\
\hline 12 & 2 & 1 & 3 & 1 & 2 & 122 & 21.7272 & 33.3 & -30.449 & 1.4 & -2.9226 \\
\hline 13 & 2 & 2 & 1 & 3 & 1 & 14.4 & 23.16725 & 28.5 & -29.097 & 13 & -22789 \\
\hline 14 & 2 & 2 & 2 & 1 & 2 & 13.6 & 22.67078 & 25 & -27959 & 1.1 & -0.8279 \\
\hline 15 & 2 & 2 & 3 & 2 & 3 & 12.4 & 21.86843 & 30 & -29.542 & 1.6 & -4.0824 \\
\hline 16 & 2 & 3 & 1 & 1 & 2 & 12.2 & 21.7272 & 40 & -32.041 & 1.8 & -5.1055 \\
\hline 17 & 2 & 3 & 2 & 2 & 3 & 12.2 & 21.7272 & 333 & -30.449 & 1.2 & -1.5836 \\
\hline 18 & 2 & 3 & 3 & 3 & 1 & 14 & 2292256 & 333 & -30.449 & 13 & -22789 \\
\hline 19 & 3 & 1 & 1 & 3 & 2 & 10.8 & 20.66848 & 33.3 & -30.449 & 1.3 & -2.2789 \\
\hline 20 & 3 & 1 & 2 & 1 & 3 & 10.8 & 20.66848 & 33.3 & -30.449 & 1.4 & -2.9226 \\
\hline 21 & 3 & 1 & 3 & 2 & 1 & 12.4 & 21.86843 & 333 & -30.449 & 1 & 0 \\
\hline 22 & 3 & 2 & 1 & 1 & 3 & 11.6 & 21.28916 & 333 & -30.449 & 12 & -1.5836 \\
\hline 23 & 3 & 2 & 2 & 2 & 1 & 132 & 22.41148 & 25 & -27.959 & 1.2 & -1.5836 \\
\hline 24 & 3 & 2 & 3 & 3 & 2 & 14.4 & 23.16725 & 30 & -29.542 & 1.4 & -2.9226 \\
\hline 25 & 3 & 3 & 1 & 2 & 1 & 13.6 & 22.67078 & 30 & -29.542 & 13 & -2.2789 \\
\hline 26 & 3 & 3 & 2 & 3 & 2 & 12.4 & 21.86843 & 36.65 & -31.282 & 1.5 & -3.5218 \\
\hline 27 & 3 & 3 & 3 & 1 & 3 & 11.6 & 21.28916 & 32.45 & -30.224 & 1.4 & -29226 \\
\hline
\end{tabular}




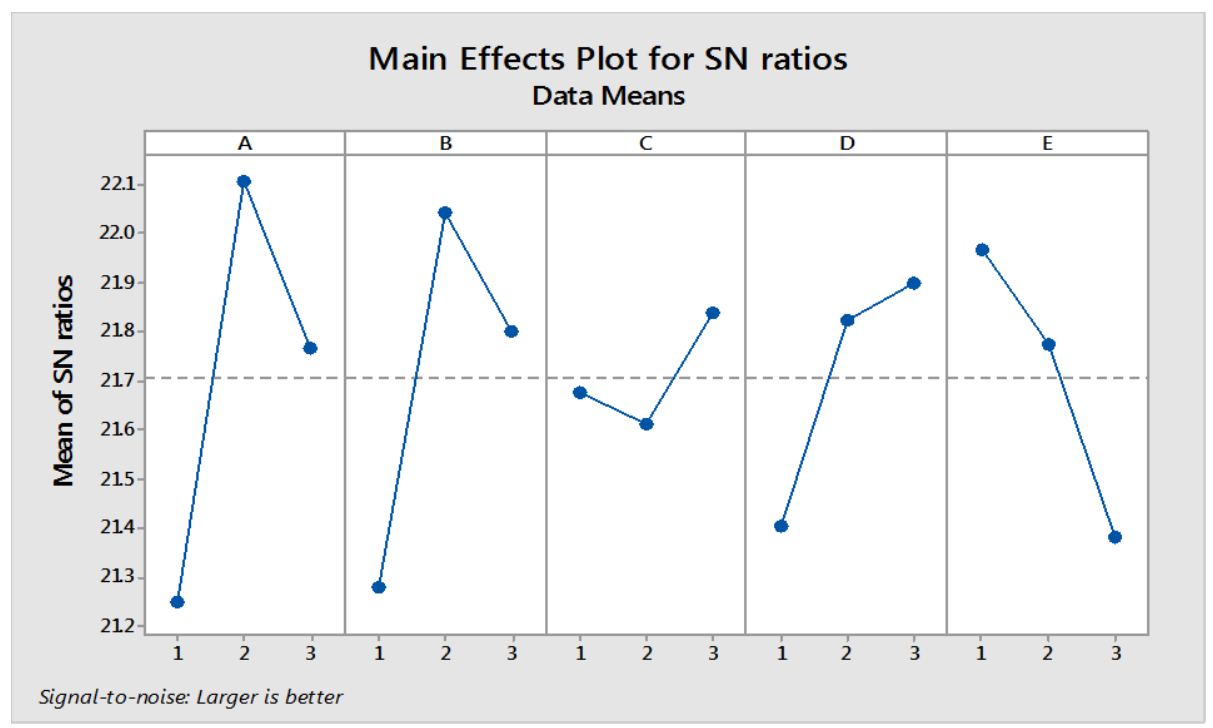

Figure 5 Taguchi Analysis: Effect of control factors on $B_{w}$

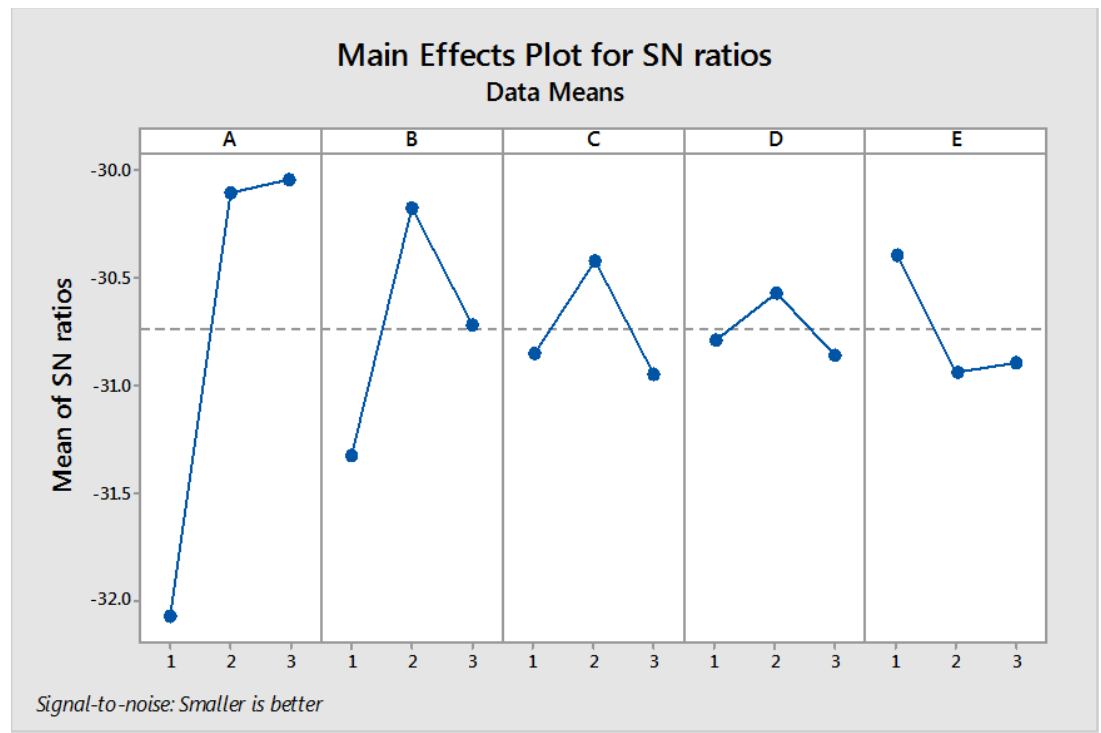

Figure 6 Taguchi Analysis: Effect of control factors on $D_{i}$

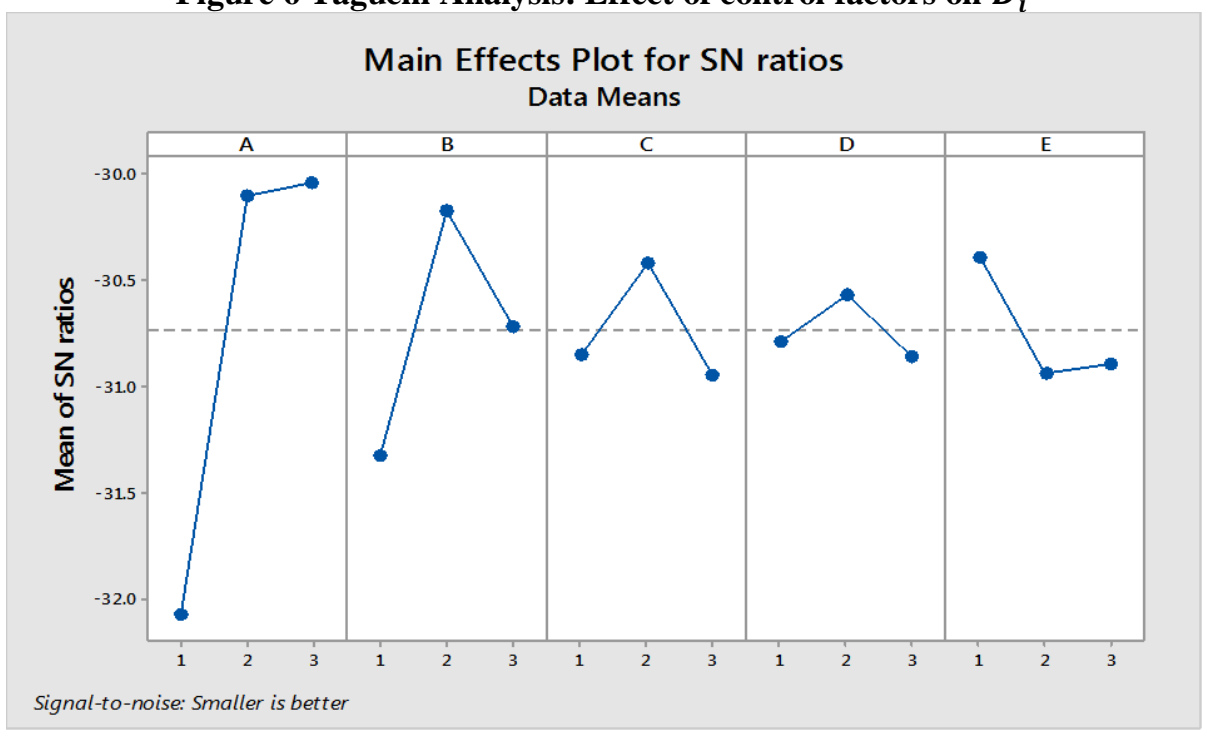

Figure 7 Taguchi Analysis: Effect of control factors on $D_{H}$ 
Larger is better

Table 4 Response Table for Signal to Noise Ratios of $B_{w}$

\begin{tabular}{|c|c|c|c|c|c|c|c|c|c|c|c|}
\hline Level & A & B & $(\mathrm{AxB})$ & $\left.{ }_{1} \mathrm{AxB}\right)_{2}$ & $\mathrm{C}$ & $(\mathrm{BxC})_{1}($ & $(\mathrm{BxC})_{2}$ & $(\mathrm{AxC})_{1}$ & $(\mathrm{AxC})_{2}$ & D & E \\
\hline 1 & 21.25 & 21.28 & 21.68 & 21.40 & 21.97 & 21.85 & 21.88 & 21.70 & 21.78 & 21.58 & 21.71 \\
\hline 2 & 22.11 & 22.04 & 21.61 & 21.82 & 21.77 & 21.62 & 21.49 & 21.85 & 21.65 & 21.66 & 21.56 \\
\hline 3 & 21.77 & 21.80 & 21.84 & 21.90 & 21.38 & 21.66 & 21.75 & 21.57 & 21.70 & 21.88 & 21.85 \\
\hline Delta & 0.86 & 0.77 & 0.23 & 0.50 & 0.59 & 0.23 & 0.39 & 0.28 & 0.13 & 0.30 & 0.30 \\
\hline Rank & 1 & 2 & 10 & 4 & 3 & 9 & 5 & 8 & 11 & 6 & 7 \\
\hline
\end{tabular}

Smaller is better

Table5:Response Table for Signal to Noise Ratios of $\% D_{i}$

\begin{tabular}{llllllllllll}
\hline Level & $\mathrm{A}$ & $\mathrm{B}$ & $(\mathrm{AxB})_{1}$ & $(\mathrm{AxB})_{2}$ & $\mathrm{C}$ & $(\mathrm{BxC})_{1}$ & $(\mathrm{BxC})_{2}$ & $(\mathrm{AxC})_{1}$ & $(\mathrm{AxC})_{2} \mathrm{D}$ & $\mathrm{E}$ & \\
\hline 1 & -32.08 & -31.33 & -30.85 & -30.79 & -30.39 & -31.13 & -30.76 & -30.64 & -30.52 & -30.81 & -30.40 \\
2 & -30.10 & -30.17 & -30.41 & -30.56 & -30.93 & -31.05 & -31.26 & -30.77 & -30.67 & -30.87 & -30.78 \\
3 & -30.04 & -30.71 & -30.95 & -30.86 & -30.89 & -30.04 & -30.19 & -30.80 & -31.02 & -30.54 & -31.0 \\
Delta & 2.04 & 1.15 & 0.53 & 0.30 & 0.55 & 1.08 & 1.06 & 0.15 & 0.49 & 0.33 & 0.62 \\
Rank & 1 & 2 & 7 & 10 & 6 & 3 & 4 & 11 & 8 & 9 & 5 \\
\hline
\end{tabular}

Smaller is better

Table 6: Response Table for Signal to Noise Ratios of $D_{H}$

\begin{tabular}{lccccccccccc}
\hline Level & $\mathrm{A}$ & $\mathrm{B}$ & $(\mathrm{AxB})_{1}$ & $(\mathrm{AxB})_{2}$ & $\mathrm{C}$ & $(\mathrm{BxC})_{1}$ & $(\mathrm{BxC})_{2}(\mathrm{AxC})_{1}(\mathrm{AxC})_{2}$ & $\mathrm{D}$ & $\mathrm{E}$ & \\
\hline 1 & -2.615 & -2.306 & -2.653 & -2.850 & -2.301 & -2.427 & -2.522 & -2.749 & -2.068 & -2.964 & -2.393 \\
2 & -2.769 & -2.296 & -2.316 & -2.204 & -2.774 & -2.764 & -2.395 & -2.626 & -2.545 & -2.477 & -3.218 \\
3 & -2.224 & -3.006 & -2.640 & -2.554 & -2.534 & -2.417 & -2.692 & -2.234 & -2.996 & -2.167 & -1.998 \\
Delta & 0.546 & 0.711 & 0.337 & 0.646 & 0.473 & 0.346 & 0.297 & 0.515 & 0.928 & 0.797 & 1.220 \\
Rank & 6 & 4 & 10 & 5 & 8 & 9 & 11 & 7 & 2 & 3 & 1 \\
\hline
\end{tabular}

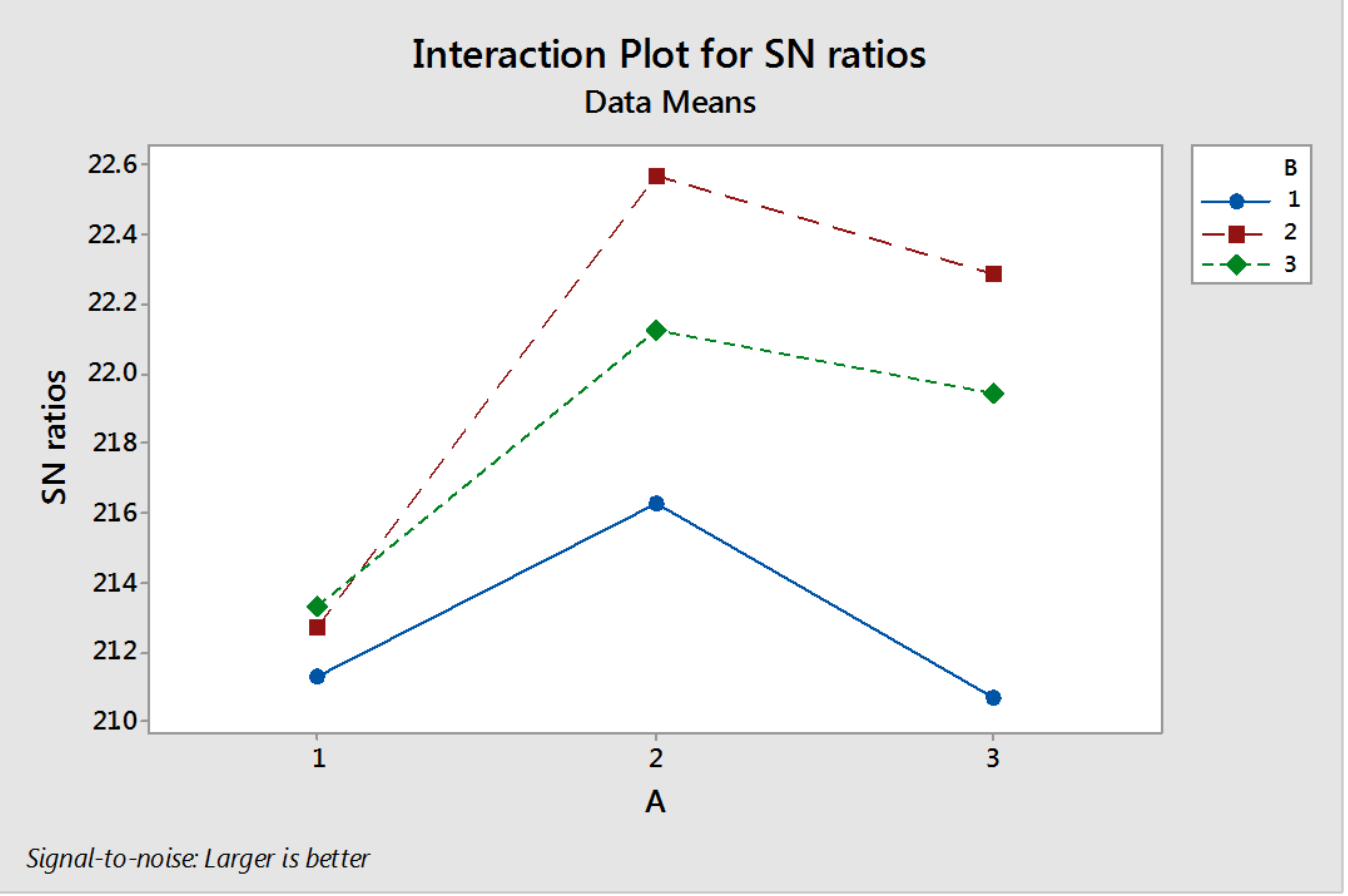

Figure 8 Interaction graph between $\mathrm{A} \times \mathrm{B}$ for $\boldsymbol{B}_{w}$ 


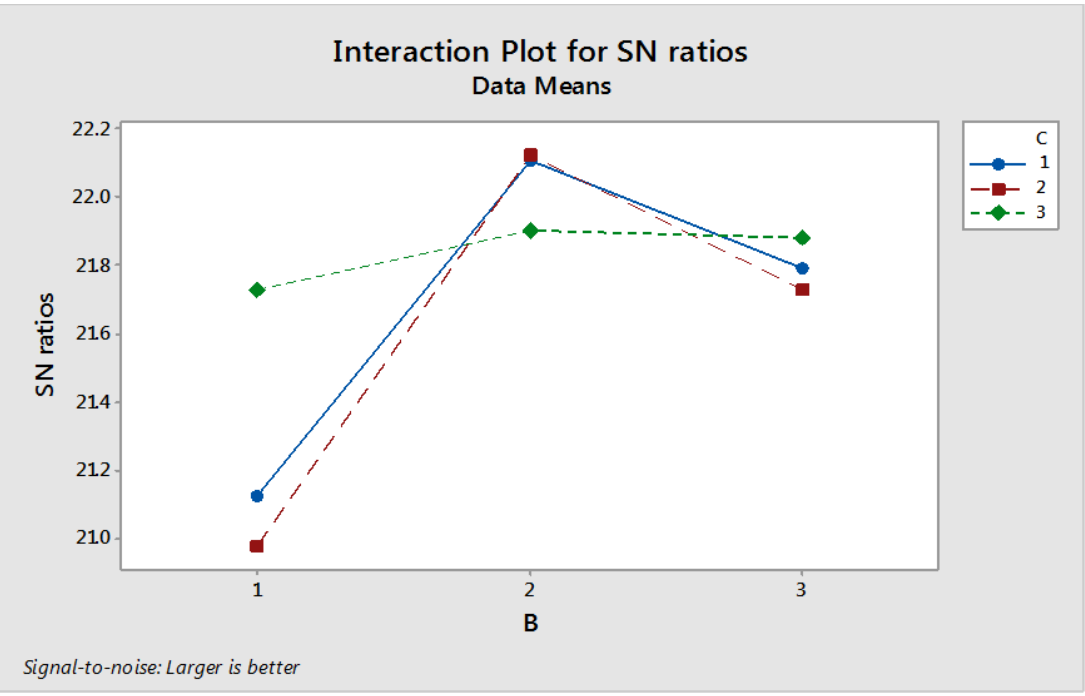

Figure 9 Interaction graph between $\mathrm{B} \times \mathrm{C}$ for $\boldsymbol{B}_{w}$

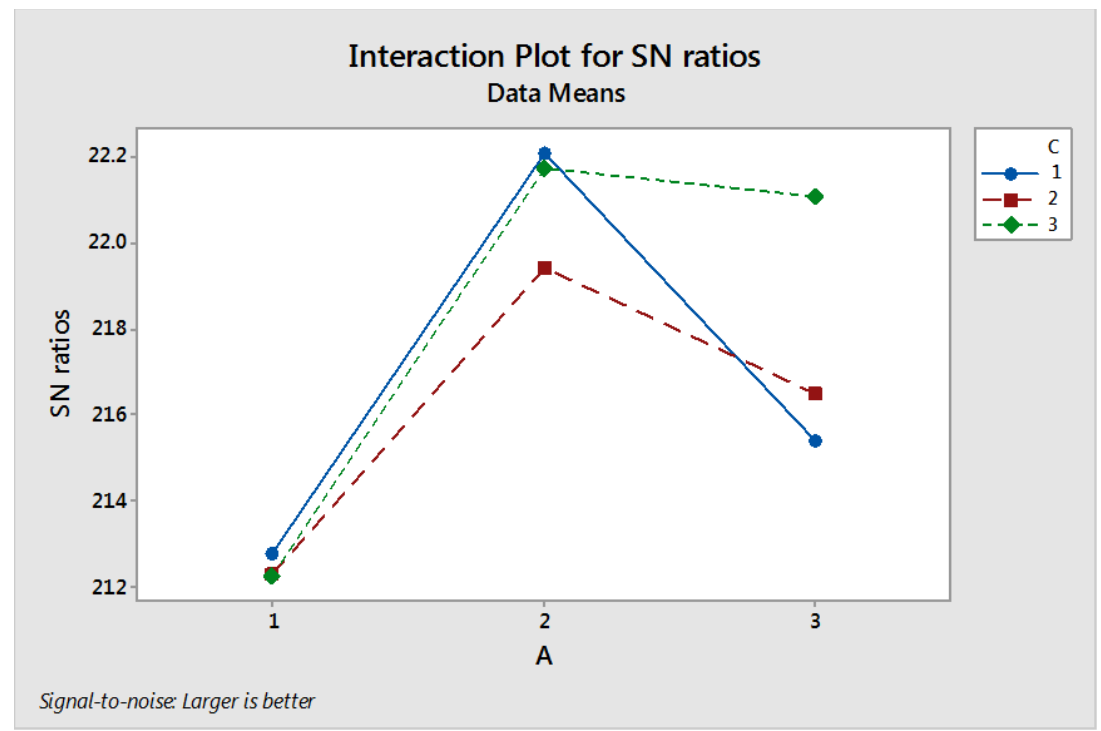

Figure 10 Interaction graph between $\mathrm{A} \times \mathrm{C}$ for $\boldsymbol{B}_{w}$

Similar reasoning can be applied to analysis of performance measures $B_{w}$. The interaction graphs for A $\mathrm{x} \mathrm{B}, \mathrm{B} \times \mathrm{C}$ and $\mathrm{A} \times \mathrm{C}$ on $D_{i}$ are shown in the figure 11, 12 and 13 respectively. It is observed from the response table (table 5) that factors $\mathrm{A}, \mathrm{D}$ and $\mathrm{E}$ have the least contribution to minimization of $B_{w}$. However, interaction between factors $\mathrm{A}$ and $\mathrm{B}, \mathrm{B}$ and $\mathrm{C}$, and $\mathrm{A}$ and $\mathrm{C}$ cannot be neglected. Therefore, the recommended settings for minimization of $B_{w}$ are at levels $A_{3}, B_{2}, C_{2}, D_{2}$ and $E_{1}$ with due consideration given to interaction effects.

As far as minimization of depth of HAZ is concerned, factor B is most important factor among all the factors, whereas factor $\mathrm{C}$ has least impact as shown in the response table (table 6). However, the interaction of factors $\mathrm{A} \times \mathrm{B}, \mathrm{B} \times \mathrm{C}$ and $\mathrm{A} \times \mathrm{C}$ on $D_{H}$ are shown in the interaction graphs of figure 14,15 and 16 respectively cannot be neglected. Although the effects of factors A C and D seems to be less significant, factors A and B show significant effect compared to any other interaction. Hence the optimal factor combination for minimization of Depth of $\mathrm{HAZ}$ can be given by $A_{3}, B_{2}, C_{2}, D_{3}$ and $E_{1}$.

Analysis of variance (ANOVA) of the experimental data for the responses for bead width, dilution and depth of HAZ was carried out to check the statistical significanceof the conclusions already drawn based on a simple analysis of means. The ANOVA tables (tables 7, 8 and 9) show the influence of various process parameters and their interactions of responses. Analysis was undertaken at a level of significance of $5 \%$. 


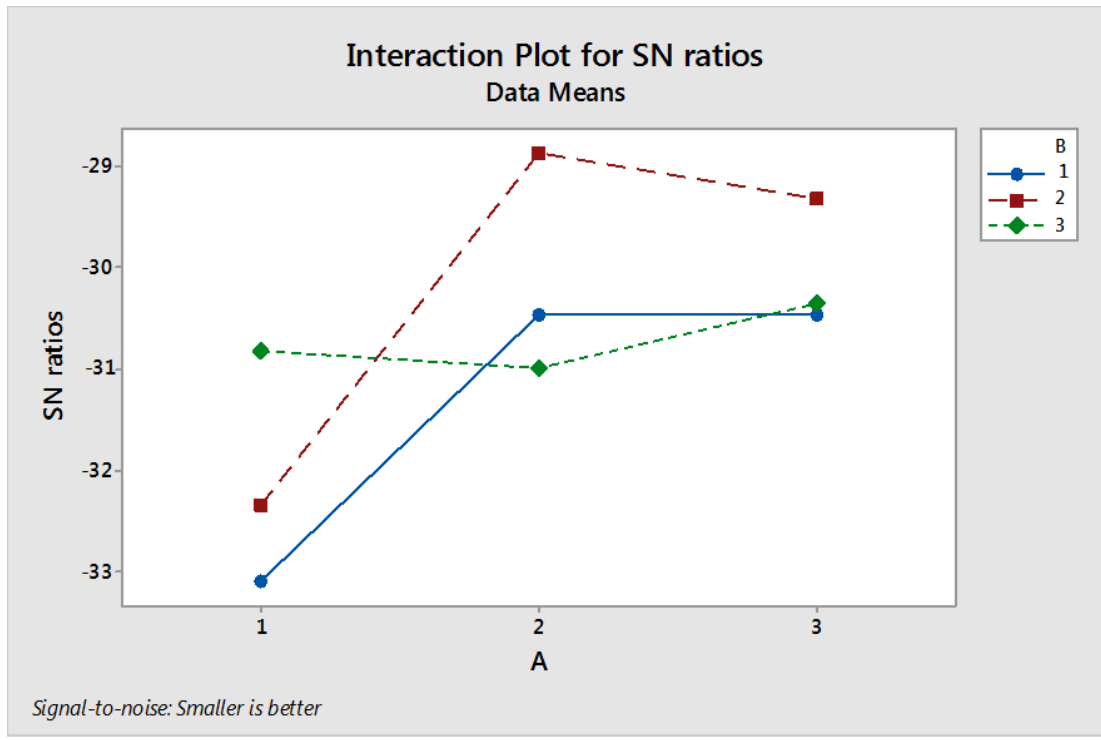

Figure 11 Interaction graph between $\mathrm{A} \times \mathrm{B}$ for $D_{i}$

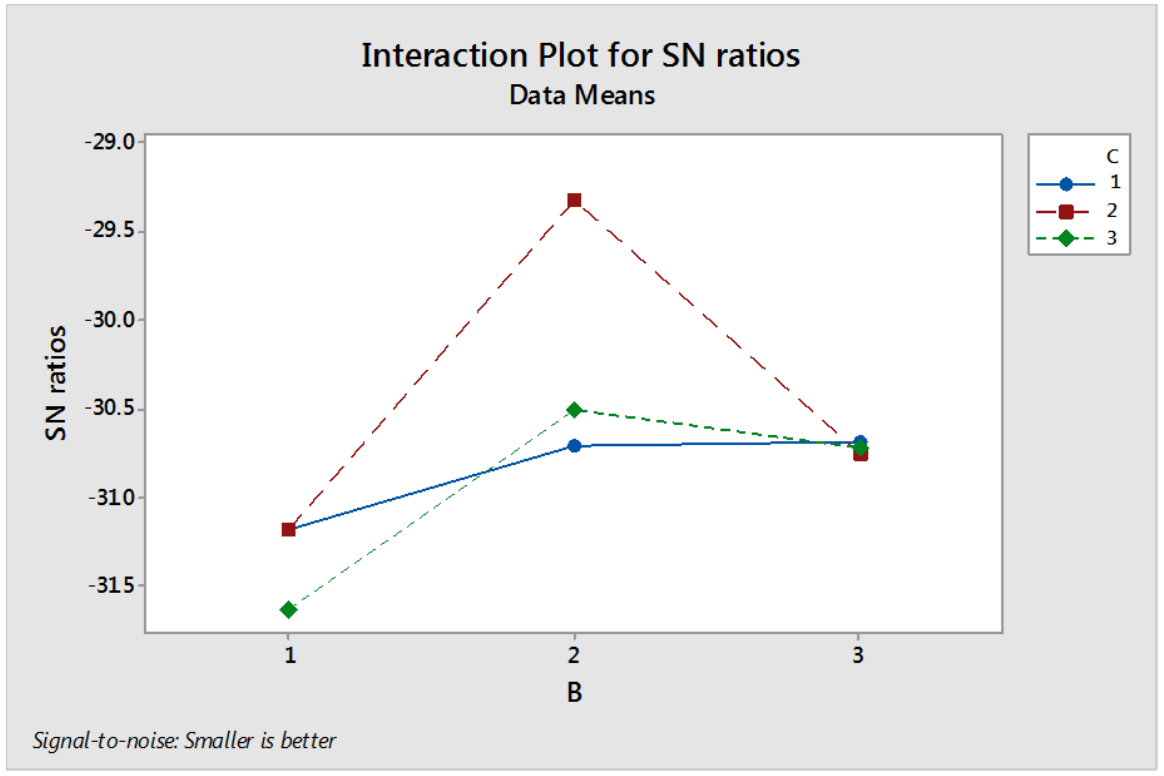

Figure 12 Interaction graph between $\mathrm{B} \times \mathrm{C}$ for $D_{i}$

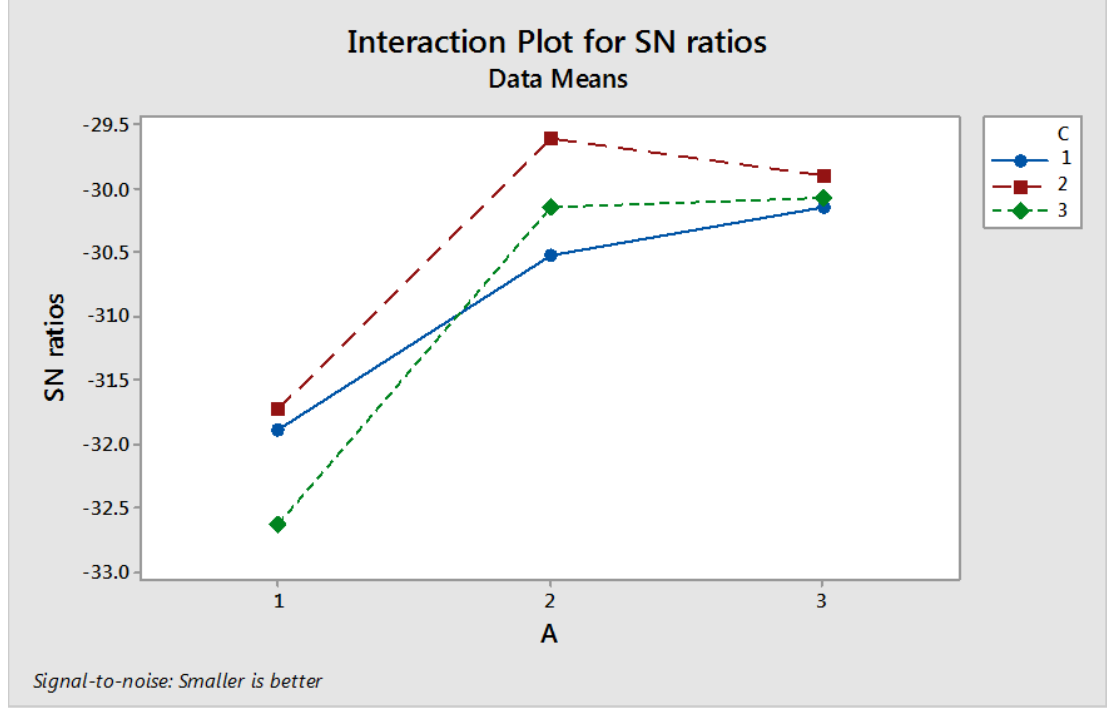

Figure 13 Interaction graph between $\mathrm{A} \times \mathbf{C}$ for $D_{i}$ 


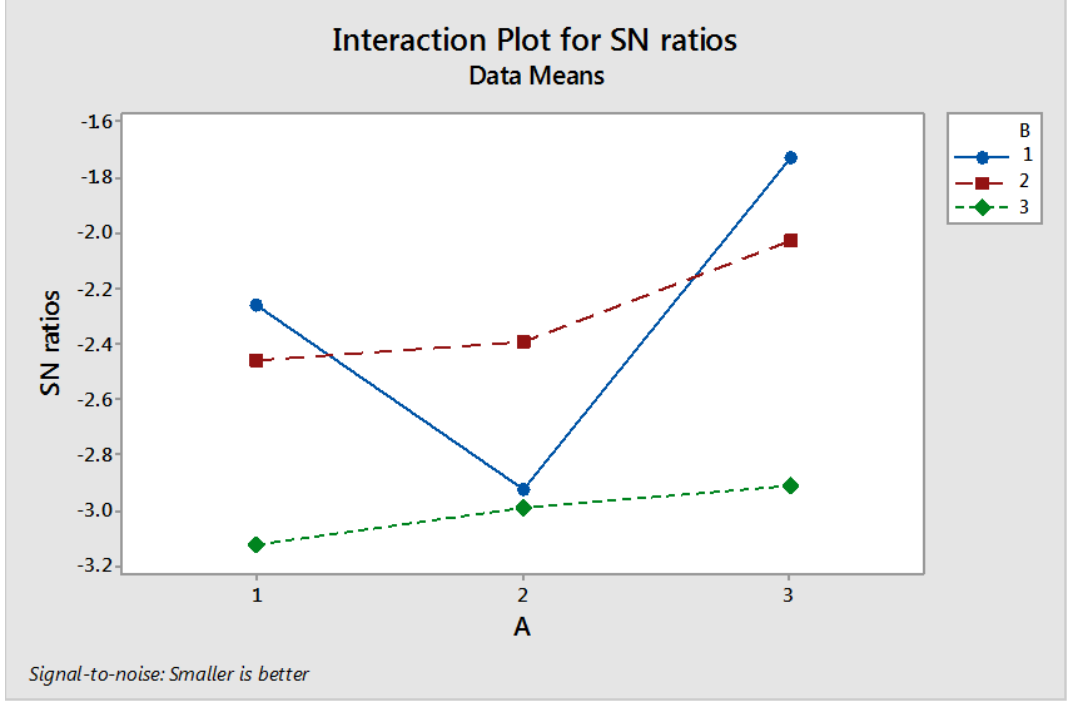

Figure 14 Interaction graph between A x B for $D_{H}$

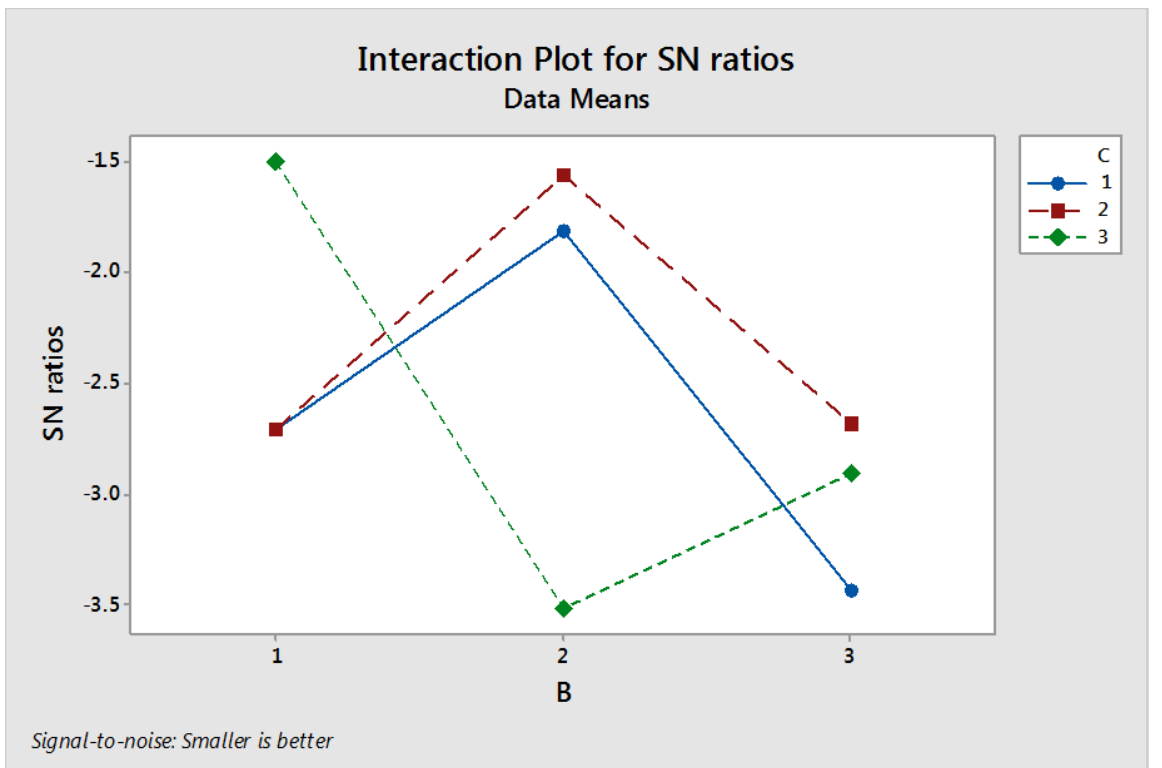

Figure 15 Interaction graph between $\mathrm{B}$ x $\mathrm{C}$ for $D_{H}$ Interaction Plot for SN ratios Data Means

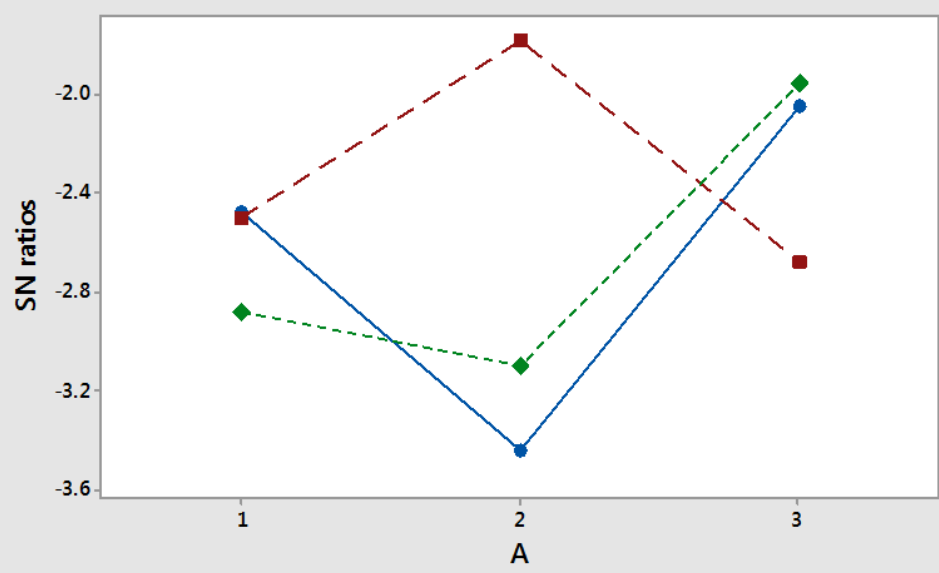

Signal-to-noise: Smaller is better

Figure 16 Interaction graph between $\mathrm{A}$ x $\mathrm{C}$ for $D_{H}$ 
From the last column of table 7, it can be concluded that wire feed rate (0.706), Arc Voltage (0.695), Nozzle to Plate Distance (0.470) have great influence on bead width. While interaction of wire feed rate and Arc Voltage (0.850) and Arc Voltage and welding speed (0.603) cause significance contribution to bead width, the factor welding speed (0.913) and the interaction between the wire feed rate and welding speed (0.996) show less significance.

Table 7: ANOVA tablefor Bead width $\left(B_{w}\right)$

\begin{tabular}{llrrrr}
\hline Source & $\begin{array}{c}\text { Degree of } \\
\text { Freedom }(D F)\end{array}$ & $\begin{array}{c}\text { Sum of Squares } \\
(S S)\end{array}$ & $\begin{array}{r}\text { Mean Square } \\
(M S)\end{array}$ & $\begin{array}{r}\text { F-statistics } \\
(F)\end{array}$ & $(P)$ \\
\hline A & 2 & 0.0042 & 0.00211 & 0.39 & 0.706 \\
B & 2 & 0.0044 & 0.00221 & 0.41 & 0.695 \\
C & 2 & 0.0010 & 0.00050 & 0.09 & 0.913 \\
D & 2 & 0.0105 & 0.00527 & 0.98 & 0.470 \\
E & 2 & 0.0002 & 0.00008 & 0.01 & 0.986 \\
A B & 4 & 0.0069 & 0.00172 & 0.32 & 0.850 \\
A C & 4 & 0.0008 & 0.00020 & 0.04 & 0.996 \\
B C & 4 & 0.0169 & 0.00423 & 0.79 & 0.603 \\
Error & 3 & 0.0161 & 0.00537 & & \\
Total & 26 & 28.7941 & & & \\
\hline
\end{tabular}

Table8indicates that, the Arc Voltage (0.092), welding speed (0.418), Nozzle to Plate Distance (0.726) have great influence on dilution. The interaction of Arc Voltage and welding speed (0.606) cause significant contribution to dilution, whereas the interaction between wire feed rate and Arc Voltage (0.070) and that between the wire feed rate and welding speed (0.616), along with the factor wire feed rate $(0.007)$ have less significant effect on dilution.

Table 8: ANOVA table for $\%$ Dilution $\left(\% D_{i}\right)$

\begin{tabular}{|c|c|c|c|c|c|}
\hline $\begin{array}{l}\text { Source } \\
\text { Freed }\end{array}$ & $\begin{array}{l}\text { Degree of } \\
\text { om (DF) }\end{array}$ & f & $\begin{array}{l}\text { f Squares Mean Square } \\
\qquad(\mathrm{MS})\end{array}$ & $\begin{array}{l}\text { F-statistics } \\
\qquad(\mathrm{P})\end{array}$ & Probability \\
\hline A & 2 & 422.087 & 211.043 & 21.82 & 0.007 \\
\hline B & 2 & 88.649 & 44.324 & 4.58 & 0.092 \\
\hline $\mathrm{C}$ & 2 & 21.134 & 10.567 & 1.09 & 0.418 \\
\hline $\mathrm{D}$ & 2 & 6.702 & 3.351 & 0.35 & 0.726 \\
\hline $\mathrm{E}$ & 2 & 25.872 & 12.936 & 1.34 & 0.359 \\
\hline$A * B$ & 4 & 200.791 & 50.198 & 5.19 & 0.070 \\
\hline$A^{*} \mathrm{C}$ & 4 & 28.224 & 7.056 & 0.73 & 0.616 \\
\hline $\mathrm{B} * \mathrm{C}$ & 4 & 29.076 & 7.269 & 0.75 & 0.606 \\
\hline Error & 4 & 38.681 & 9.670 & & \\
\hline Total & 26 & 861.215 & & & \\
\hline
\end{tabular}

Similarly it is obvious from the table 9 that the arc voltage $(0.315)$, wire feed rate( 0.523$)$ and nozzle to plate distance $(0.459)$ have great influence on depth of HAZ. The interaction between wire feed rate and arc voltage (0.937) and arc voltage and welding speed(0.208) show significant contribution to depth of HAZ, whereas the factor welding speed (0.700) and the interaction between wire feed rate and welding speed (0.395) have less contribution to the response ie depth of $\operatorname{HAZ}\left(D_{H}\right)$ 
Table 9: ANOVA table for Depth of HAZ $\left(D_{H}\right)$

\begin{tabular}{ccllcc}
\hline Source & $\begin{array}{c}\text { Degree of } \\
\text { Freedom (DF) }\end{array}$ & \multicolumn{2}{l}{ Sum of Squares } \\
$(\mathrm{SS})$ & $\begin{array}{l}\text { Mean Square } \\
(\mathrm{MS})\end{array}$ & $\begin{array}{l}\text { F-statistics } \\
(\mathrm{F})\end{array}$ & $\begin{array}{c}\text { Probability } \\
(\mathrm{P})\end{array}$ \\
\hline $\mathrm{A}$ & 2 & 0.03630 & 0.018148 & 0.77 & 0.523 \\
$\mathrm{~B}$ & 2 & 0.07407 & 0.037037 & 1.56 & 0.315 \\
$\mathrm{C}$ & 2 & 0.01852 & 0.009259 & 0.39 & 0.700 \\
$\mathrm{D}$ & 2 & 0.04519 & 0.022593 & 0.95 & 0.459 \\
$\mathrm{E}$ & 2 & 0.02741 & 0.013704 & 0.58 & 0.602 \\
$\mathrm{~A}^{* \mathrm{~B}}$ & 4 & 0.01704 & 0.004259 & 0.18 & 0.937 \\
$\mathrm{~A}^{*} \mathrm{C}$ & 4 & 0.12593 & 0.031481 & 1.33 & 0.395 \\
$\mathrm{~B}^{*} \mathrm{C}$ & 4 & 0.22815 & 0.057037 & 2.41 & 0.208 \\
Error & 4 & 0.09481 & 0.023704 & & \\
Total & 26 & 0.66741 & & & \\
\hline
\end{tabular}

\section{Confirmation Experiment}

The optimal contribution of welding process parameters has been determined for three responses commonly used or hardfacing through MIG in the previous section. However, any design of experiment strategy emphasizes conducting a confirmation experiment. Therefore, new combinations of welding process parameters are used for verification or confirmation experiments and necessary predictive equations are developed. The estimated S/N ratio for bead width can be calculated with the help of the following prediction equation:

$$
\begin{aligned}
& \hat{\eta}_{1}=\bar{T}+\left(\bar{A}_{2}-\bar{T}\right)+\left(\bar{B}_{2}-\bar{T}\right)+\left[\left(\bar{A}_{2} \bar{B}_{2}-\bar{T}\right)-\left(\bar{A}_{2}-\bar{T}\right)-\left(\bar{B}_{2}-\bar{T}\right)\right]+\left(\bar{C}_{3^{-}} \bar{T}\right)+\left[\left(\bar{B}_{2} \bar{C}_{3}-\bar{T}\right)-\right. \\
& \left.\left(\bar{B}_{2}-\bar{T}\right)-\left(\bar{C}_{3^{-}}-\bar{T}\right)\right]+\left[\left(\bar{A}_{2} \bar{C}_{3}-\bar{T}\right)-\left(\bar{A}_{2}-\bar{T}\right)-\left(\bar{C}_{3^{-}}-\bar{T}\right)\right]+\left(\bar{D}_{3^{-}}-\bar{T}\right)+\left(\bar{E}_{1}-\bar{T}\right)
\end{aligned}
$$

$\hat{\eta}_{1}=$ Predicted average

$\bar{T}=$ Overall experimental average

$\bar{A}_{2} \bar{B}_{2} \bar{C}_{3} \bar{D}_{3}$ and $\bar{E}_{1}=$ Mean responses for factor and interaction at designated levels.

By combining like terms, the equation is reduced to:

$$
\hat{\eta}_{1}=\bar{A}_{2} \bar{B}_{2}+\bar{B}_{2} \bar{C}_{3}+\bar{A}_{2} \bar{C}_{3}-\bar{A}_{2}-\bar{B}_{2}-\bar{C}_{3}+\bar{D}_{3}+\bar{E}_{1}-\bar{T}
$$

A new combination of factors levels is $\bar{A}_{2}, \bar{B}_{2}, \bar{C}_{3}, \bar{D}_{3}$ and $\bar{E}_{1}$ is used to predict Bead width through the prediction equation, and it is found to be $\hat{\eta}_{1}=21.96 \mathrm{~dB}$

Similarly, a prediction equation is developed for estimating the $\mathrm{S} / \mathrm{N}$ Ratio of Dilution, given in equation (9):

$$
\begin{aligned}
& \left.\hat{\eta}_{2}=\bar{T}+\left(\bar{A}_{3}-\bar{T}\right)+\left(\bar{B}_{2}-\bar{T}^{2}\right)+\left[\bar{A}_{3} \bar{B}_{2}-\bar{T}\right)-\left(\bar{A}_{3}-\bar{T}\right)-\left(\bar{B}_{2}-\bar{T}\right)\right]+\left(\bar{C}_{2}-\bar{T}\right)+\left[\left(\left(\bar{B}_{2} \bar{C}_{2}-\bar{T}\right)-\right.\right. \\
& \left.\left(\bar{B}_{2}-\bar{T}\right)-\left(\bar{C}_{2}-\bar{T}\right)\right]+\left[\left(\bar{A}_{3} \bar{C}_{2}-\bar{T}\right)-\left(\bar{A}_{3}-\bar{T}\right)-\left(\bar{C}_{2}-\bar{T}\right)\right]+\left(\bar{D}_{2}-\bar{T}\right)+\left(\bar{E}_{1}-\bar{T}\right)
\end{aligned}
$$

$\hat{\eta}_{2}=$ Predicted average

$\bar{T}=$ Overall experimental average

$\bar{A}_{3} \bar{B}_{2} \bar{C}_{2} \bar{D}_{2}$ and $\bar{E}_{1}=$ Mean responses for factor and interaction at designated levels.

By combining like terms, the equation is reduced to:

$\hat{\eta}_{2}=\bar{A}_{3} \bar{B}_{2}+\bar{B}_{2} \bar{C}_{2}+\bar{A}_{3} \bar{C}_{2}-\bar{A}_{3}-\bar{B}_{2}-\bar{C}_{2}+\bar{D}_{2}+\bar{E}_{1}-\bar{T}$

A new combination of factors levels is $\bar{A}_{3} \bar{B}_{2} \bar{C}_{2} \bar{D}_{2}$ and $\bar{E}_{1}$ is used to predict \% Dilution through the prediction equation, and it is found to be $\hat{\eta}_{2}=-30.30 \mathrm{~dB}$

Similarly, a prediction equation is developed for estimating the S/N Ratio of Depth of HAZ, given in equation (11):

$$
\begin{aligned}
& \hat{\eta}_{3}=\bar{T}+\left(\bar{A}_{3}-\bar{T}\right)+\left(\bar{B}_{2}-\bar{T}\right)+\left[\left(\bar{A}_{3} \bar{B}_{2}-\bar{T}\right)-\left(\bar{A}_{3}-\bar{T}\right)-\left(\bar{B}_{2}-\bar{T}\right)\right]+\left(\bar{C}_{2}-\bar{T}\right)+\left[\left(\left(\bar{B}_{2} \bar{C}_{2}-\bar{T}\right)-\right.\right. \\
& \left.\left(\bar{B}_{2^{-}} \quad \bar{T}\right)-\left(\bar{C}_{2}-\bar{T}\right)\right]+\left[\left(\bar{A}_{3} \bar{C}_{2}-\bar{T}\right)-\left(\bar{A}_{3}-\bar{T}\right)-\left(\bar{C}_{2}-\bar{T}\right)\right]+\left(\bar{D}_{3}-\bar{T}\right)+\left(\bar{E}_{1}-\bar{T}\right)
\end{aligned}
$$

$\hat{\eta}_{3}=$ Predicted average

$\bar{T}=$ Overall experimental average

$\bar{A}_{3} \bar{B}_{2} \bar{C}_{2} \bar{D}_{3}$ and $\bar{E}_{1}=$ Mean responses for factor and interaction at designated levels.

By combining like terms, the equation is reduced to:

$$
\hat{\eta}_{3}=\bar{A}_{3} \bar{B}_{2}+\bar{B}_{2} \bar{C}_{2}+\bar{A}_{3} \bar{C}_{2}-\bar{A}_{3}-\bar{B}_{2}-\bar{C}_{2}+\bar{D}_{3}+\bar{E}_{1}-\bar{T}
$$

A new combination of factors levels is $\bar{A}_{3} \bar{B}_{2} \bar{C}_{2} \bar{D}_{3}$ and $\bar{E}_{1}$ is used to predict Depth of HAZ through the prediction equation, and it is found to be $\hat{\eta}_{3}=-1.99 \mathrm{~dB}$. 
For each performance characteristic, new experiments with different combinations of factors and their levels were conducted and compared with the result obtained from the predictive equations as shown in Table 10. The resulting model seems to be capable of predicting $B_{w}, D_{i}$ and $D_{H}$ to a reasonable accuracy.

Table 10: Results of confirmation experiments

\begin{tabular}{l}
$\begin{array}{c}\text { Confirmation experiment } \\
\text { For } B_{w}\end{array}$ \\
$\begin{array}{c}\text { Confirmation experiment } \\
\text { for } D_{i}\end{array}$ \\
\hline Prediction \\
Level $\bar{A}_{2} \bar{B}_{2} \bar{C}_{3} \bar{D}_{3} \bar{E}_{1} \bar{A}_{2} \bar{B}_{2} \bar{C}_{3} \bar{D}_{3} \bar{E}_{1} \bar{A}_{3} \bar{B}_{2} \bar{C}_{2} \bar{D}_{2} \bar{E}_{1} \bar{A}_{3} \bar{B}_{2} \bar{C}_{2} \bar{D}_{2} \bar{E}_{1} \bar{A}_{3} \bar{B}_{2} \bar{C}_{2} \bar{D}_{3} \bar{E}_{1} \bar{A}_{3} \bar{B}_{2} \bar{C}_{2} \bar{D}_{3} \bar{E}_{1}$
\end{tabular}

\section{References}

[1]. G.R.C.Pradeep, A.Ramesh, B. Durga Prasad. A Review Paper on Hard Facing Processes and Materials. International Journal of Engineering Science and Technology vol 2(11), 2010, 6507 -6510.

[2]. M.F. Buchely The effect of microstructure on abrasive wear of hardfacing alloys, J.C Gutierrez, L.M Le on, A.Taro. Tribology and Surfaces Group, National University of Colombia, Medell in Colombia Received 2 August 2004

[3]. Bipin Kumar Srivastava. A Review on Arc Welding Parameters on Mechanical Behavior of Ferrous Metals/Alloys. International Journal of Engineering science and technology. Vol 2(5), 2010, 1425 - 1432.

[4]. M.Bakilkaramis*, K.Yildzili*, Erosion behaviour of Hardfaced AISI 1020 steel

[5]. Firat University, Department of Metallurgy and Materials Engineering, 23119, Elazig,

[6]. Turkey

[7]. G.G. Garrett, G.J. Wright:I:, J.L. Henderson, and T. ellis A preliminary assessment of the factors responsible for the abrasi ve-wear resistance of some weld-deposited hard facings* J. S. At. Inst. Min. Metal/., vol. 86, no. 11. Nov. 1986. pp. $455-462$.

[8]. R. Chotěborský1, P. Hrabě1, M. Müller1, R. Válek2, J. Savková3, M. Jirka1, —Effect of rbide size in hard facing on abrasive wear Department of Material Science and Manufacturing Technology, Faculty of ngineering, Czech University of Life Sciences Prague, Prague, Czech Republic 2SVUM Ltd., Czech Republic3New Technologies Research Centre in West bohemian Region NTC,University of West Bohemia, Pilsen, Czech Republic

[9]. SauravDatta, AsishBandyopadhyay, Pradip Kumar Pal. Grey bases Taguchi method for optimization of bead geometry in submerged arc bead-on-plate welding. International Journal of Advance Manufacturing Technology (2008) 39:1136-1143.

[10]. Goutam Nandi, SuravDatta, AsishBandyopafhyay, Pradeep kumar Pal. Analysis of hybrid Taguchi methods for optimization of submerged arc weld joining processes. Challenges for quality, design and development march 5-6, 2010, NIT Agartala Tripura

[11]. K. Kishore, P. V. Gopal Krishna, K. Veladri and Syed QasimAli.Analysis of defects in gas shielded arc welding of aisi1040 steel using taguchi method Journal of Engineering and Applied Science VOL. 5, NO. 1, JANUARY 2010 ISSN $1819-6608$ ARPN Department of Mechanical Engineering, Vasavi college of Engineering, Ibrahim Bagh, Hyderabad, India

[12]. T. Yıldız, A.K. GürFıratÜniversitesiTeknikEğitimFakültesi Metal EğitimiBölümü 23119 elazi. The optimization of abrasive wear behavior of fecrc coating composite with taguchi method 6th International Advanced Technologies Symposium (IATS'11), 16-18 May 2011, Elazığ, Turkey

[13]. R. Choteborskyl .Effect of MIG process parameters on the geometry and dilution of bead in the automatic surfacing, M.Navratilova2, P. Hrabel 1Department of Material Science and Manufacturing Technology.

[14]. Material science and material testing by Gupta

[15]. Welding technology by O.P.Khanna

[16]. Taguchi Techniques for Quality Engineering by Phillip J Ro 